\title{
Transformação genética da batata cultivar Achat via Agrobacterium tumefaciens.
}

\author{
Antonio Carlos Torres ${ }^{1}$; Adriana Teixeira Ferreira ${ }^{2}$; Eduardo Romano ${ }^{3}$; Mônica Kangussú Cattony ${ }^{4}$; \\ Adriana Souza Nascimento ${ }^{4}$ \\ ${ }^{1}$ Embrapa Hortaliças, C. Postal 218, 70.359-970 Brasília-DF; ${ }^{2}$ Consultora Embrapa Hortaliças, C. Postal 218, $70.359-970$ Brasília-DF; \\ ${ }^{3}$ Embrapa Recursos Genéticos e Biotecnologia, C. Postal 02372, 70.770-900 Brasília-DF; ${ }^{4}$ Bolsista CNPq/RHAE, Embrapa Hortaliças, \\ C. Postal 218, 70.359-970 Brasília-DF.
}

\section{RESUMO}

Explantes de segmentos nodais de batata (Solanum tuberosum L.) cultivar Achat provenientes da cultura in vitro foram transformados, via Agrobacterium tumefaciens, estirpe LBA4404, contendo o vetor binário pBI121 com os genes npt II e o gus-intron. A regeneração de potenciais transformantes foi feita em meio seletivo contendo $50 \mathrm{mg} . \mathrm{L}^{-1}$ de canamicina. Foram obtidas plantas expressando resistência à canamicina e atividade da b-glucuronidase. Pela análise molecular nas plantas gus+, via PCR, constatou-se a amplificação dos genes npt II. A hibridização por Southern blotting demonstrou a inserção de pelo menos uma cópia do gene introduzido.

Palavras-chave: Solanum tuberosum, regeneração, plantas transgênicas.

\section{ABSTRACT}

Genetic transformation of potato cultivar Achat by Agrobacterium tumefaciens.

Nodal segment explants of potato (Solanum tuberosum L.) cv Achat were excised from in vitro growing plants, and transformed with Agrobacterium tumefaciens LBA4404 carrying the binary vector pBI121 with $n p t I I$ and gus-intron genes. The regeneration of putative transformants was done in medium supplemented with $50 \mathrm{mg} . \mathrm{L}^{-1}$ of kanamycin. Putative transformants expressing kanamycin resistance and b-glucuronidase activity were identified. PCR analysis of these plants showed amplification of the $n p t I I$ in gus $^{+}$plants. Southern blotting hybridization revealed the insertion of at least one copy of the $n p t$ II gene.

Keywords: Solanum tuberosum, regeneration, transgenic plants.

(Aceito para publicação em 17 de fevereiro de 2000)

$\mathrm{O}$ melhoramento genético tradicional da batata (Solanum tuberosum L.) é lento e defronta-se com uma gama de dificuldades. A espécie cultivada é tetraplóide com segregação polissômica, e muitas das cultivares comerciais apresentam baixa fertilidade de pólen ou não florescem (Vayda et al., 1992). Nesse cenário, a utilização das técnicas de transformação genética em batata teria a vantagem de possibilitar a incorporação, em clones considerados elites, de genes específicos que codificam características de interesse. Achat é uma das cultivares lideres no mercado nacional, no entanto, reduções nos níveis de produtividade desse genótipo têm sido reportados devido a infecção por viroses do grupo potivirus e luteovirus.

Estratégias de engenharia genética usando genes derivados de patógenos têm sido empregadas com sucesso no controle de doenças virais em diversas culturas incluindo a batata (Scholthof et al., 1993), permitindo o desenvolvimento, a curto prazo, de cultivares melhora- das a partir de clones adaptados e largamente empregados pelos agricultores.

Neste trabalho descreve-se o desenvolvimento e a aplicação de um sistema de regeneração e transformação eficiente para essa cultivar que, até então, não respondeu satisfatoriamente a protocolos de transformação.

\section{MATERIAL E MÉTODOS}

\section{Regeneração in vitro}

Foram utilizados explantes provenientes de plantas desenvolvidas in vitro, subcultivadas a cada 20 dias, em meio básico composto de sais minerais de MS (Murashige \& Skoog, 1962), 3\% de sacarose e, em mg.L L $^{-1}$ : i-inositol, 100; tiamina. $\mathrm{HCl}, 1,0$; piridoxina. $\mathrm{HCl}, 0,05$; ácido nicotínico, 0,05; glicina, 2,0. A esse meio foram adicionados, em mg. $\mathrm{L}^{-1}$ : ácido naftalenoacético, 0,05; cinetina, 0,05; ácido giberélico, 0,2 e phytagar 6.000 (Souza \& Souza, 1986). As culturas foram mantidas sob fotoperíodo de
$16 \mathrm{~h}$, densidade de fluxo de fótons de $62 \mathrm{mmolm}^{-2} \mathrm{~s}^{-1}$, a uma temperatura de $25 \pm 2^{\circ} \mathrm{C}$. Explantes de segmentos nodais e folhas dos propágulos desenvolvidos in vitro foram excisados e cultivados no meio básico suplementado com zeatina (zea) nas concentrações de $0 ; 1,25 ; 2,5$ e 5,0 mg. $\mathrm{L}^{-1}$, respectivamente.

Sensibilidade de explantes de batata a canamicina

Os explantes foliares e os de segmentos nodais foram cultivados em meio básico com 2,5 mg.L $\mathrm{L}^{-1}$ de zea e, suplementado, respectivamente, com 0 , $25,50,100$ e $200 \mathrm{mg} . \mathrm{L}^{-1}$ de canamicina (can). As culturas foram mantidas sob as mesmas condições de foto $\mathrm{e}$ termoperíodo descritas anteriormente.

Agrobacterium e condições de cultura

Foi utilizada a estirpe de Agrobacterium tumefaciens, LBA4404, contendo vetor binário pGUS-intron com os genes npt II (que confere resistência à can) e o gene gus (que expressa a atividade da b-glucuronidase). 
O meio de cultura utilizado para o crescimento bacteriano foi o LB (Luria Broth) (5 g.L $\mathrm{L}^{-1}$ de extrato de levedura, 10 g. $\mathrm{L}^{-1}$ de triptona e 10 g. $\mathrm{L}^{-1}$ de cloreto de sódio, pH 7,0) contendo os antibióticos can $\left(50 \mathrm{mg} . \mathrm{L}^{-1}\right)$, espectinomicina (100 mg. $\left.\mathrm{L}^{-1}\right)$ e rifampicina $\left(50 \mathrm{mg} . \mathrm{L}^{-1}\right)$. As culturas bacterianas para os experimentos de transformação foram inoculadas em erlenmeyers de $250 \mathrm{ml}$, com $50 \mathrm{ml}$ do meio LB com os respectivos antibióticos. As culturas foram incubadas a $28^{\circ} \mathrm{C}$, em agitador orbital de $0,175 \mathrm{~g}$ ( 150 $\mathrm{rpm}$, raio $10 \mathrm{~mm}$ ), durante $16 \mathrm{a} 20 \mathrm{~h}$, até atingirem uma densidade ótica $\left(\mathrm{OD}_{600}\right)$ entre 0,6 a 0,8 . Alíquotas de $15 \mathrm{ml}$ dessas culturas foram centrifugadas a 5.000 rpm (Beckman J2-21, rotor 20) por 10 min, a $4{ }^{\circ} \mathrm{C}$. O sobrenadante foi descartado e o sedimento foi suspendido em 15 $\mathrm{ml}$ de meio LB antes de proceder à infecção e ao co-cultivo dos explantes.

Infecção, co-cultivo, seleção e regeneração

Os explantes foram imersos em $5 \mathrm{ml}$ da suspensão bacteriana, durante $5 \mathrm{~min}$. Em seguida, os explantes foram transferidos para placas de Petri, contendo papel de filtro estéril, para eliminar o excesso de bactéria e, incubados durante, respectivamente, 24, 48, 72 e $96 \mathrm{~h}$ em meio para co-cultivo (meio básico suplementado com 2,5 mg. $\mathrm{L}^{-1}$ de zea. Após o período de co-cultivo, os explantes foram imersos por $30 \mathrm{~min}$, em $200 \mathrm{ml}$ de meio contendo macro e microelementos MS, 3\% sacarose e 200 mg. $L^{-1}$ de cefotaxima. Depois, os explantes foram transferidos para meio de seleção (meio de co-cultivo, com 50 mg. $\mathrm{L}^{-1}$ de can, $500 \mathrm{mg} . \mathrm{L}^{-1}$ de carbenicilina e 100 mg. $\mathrm{L}^{-1}$ de cefotaxima) durante, aproximadamente, 25 dias. Os explantes que iniciaram a regeneração foram transferidos para meio básico, com os respectivos antibióticos, para crescimento das brotações. Após 30 a 40 dias, os propágulos regenerados foram colocados em meio de enraizamento (macro, microelementos e vitaminas MS, acrescido de $3 \%$ de sacarose, $50 \mathrm{mg} . \mathrm{L}^{-1}$ de can e $0,05 \mathrm{mg} \cdot \mathrm{L}^{-1}$ de ácido naftalenoacético (ANA), para diferenciação e desenvolvimento do sistema radicular.

Teste de coloração histológico para a atividade de gus

A atividade da enzima bglucuronidase foi determinada de acor-

Tabela 1. Efeito de concentrações de zeatina na diferenciação de brotações em explantes foliares e de entre-nós de batata Achat*. Brasília, Embrapa Hortaliças, 1999.

\begin{tabular}{ccc}
\hline Concentração de & \multicolumn{2}{c}{ Média do número de brotações por explante } \\
\cline { 2 - 3 } zeatina (mg.L-1) & Folha & Entre-nó \\
\hline 0,00 & $0,00 \pm 0,00$ & $0,00 \pm 0,00$ \\
$1, .25$ & $0,61 \pm 0,35$ & $1,11 \pm 0,33$ \\
2,50 & $0,43 \pm 0,22$ & $3,50 \pm 0,40$ \\
5,00 & $0,44 \pm 0,20$ & $3,25 \pm 0,2$ \\
\hline
\end{tabular}

*A análise estatística foi feita baseando-se no erro padrão da média.

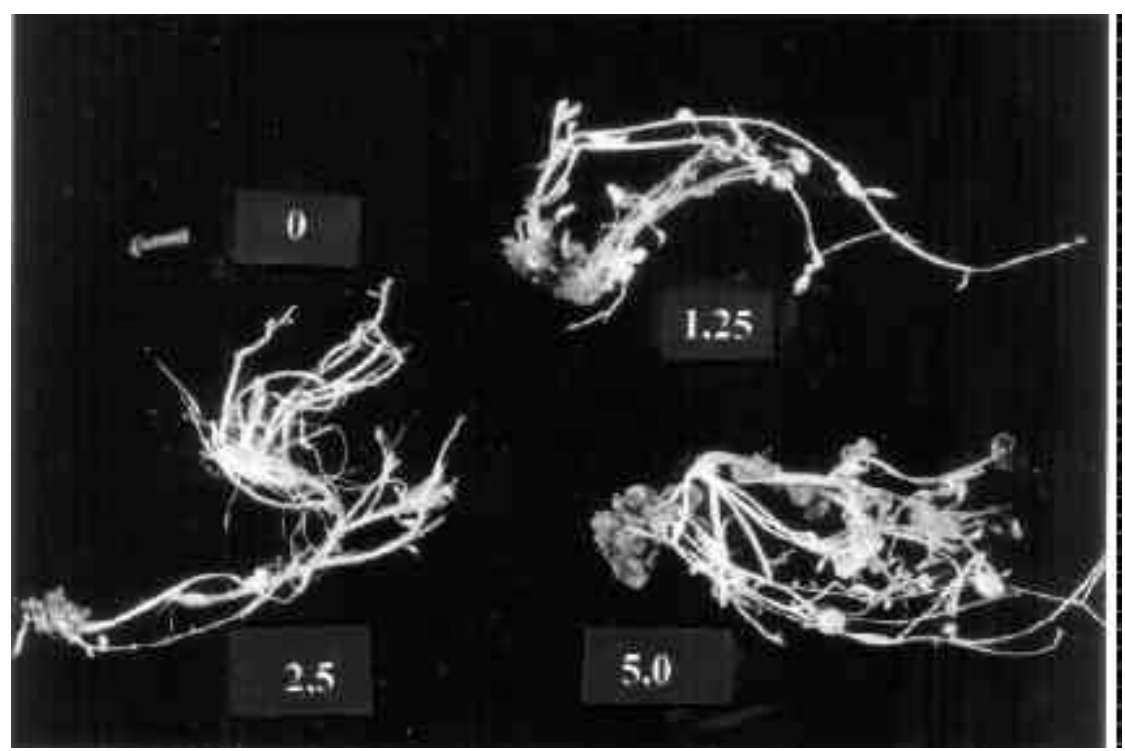

Figura 1. Efeito da concentração de zeatina, em mg.. $\mathrm{L}^{-1}$, na regeneração de brotações em explantes de segmentos nodais de batata Achat. Brasília, Embrapa Hortaliças, 1999.

do com o procedimento adaptado de Jefferson (1987). O substrato empregado foi o 5-bromo-4-cloro-3-indolilglucuranida (X-Glu, Jersey Lab and Glove Supply, Linvingston, NJ, USA). Um total de $5 \mathrm{mg}$ de X-Glu foi dissolvido em 0,02 $\mathrm{ml}$ de dimetilformamida e adicionado a seguinte solução: $2,5 \mathrm{ml}$ de fosfato de sódio $0,2 \mathrm{M} ; 2,3 \mathrm{ml}$ de água deionizada ; 0,025 $\mathrm{ml}$ de ferricianeto de potássio $0,1 \mathrm{M} ; 0,025 \mathrm{ml}$ de ferrocianeto de potássio 0,1 M; 0,10 $\mathrm{ml}$ de EDTA de sódio 0,5 M; e $0,10 \mathrm{ml}$ de triton $10 \%$. Propágulos e tecidos foram incubados nessa solução a $37^{\circ} \mathrm{C}$ por 4 a $6 \mathrm{~h}$.

\section{Análise molecular via PCR}

O DNA total das plantas resistentes à can foi obtido a partir do método descrito por Edwards et al. (1991). Foi utilizado o par de primers: 5' GAGGCTATTCGGCTATGACTG-3' e 5'TCGACAAGACCGGCTTCCCATC3' que amplificam um fragmento de 460 pb do gene nptII. A mistura de reação (25ml) continha $50 \mathrm{mM}$ de $\mathrm{KCl} ; 1,5 \mathrm{mM}$ de $\mathrm{MgCl}_{2}$ e $10 \mathrm{mM}$ de Tris- $\mathrm{HCl} \mathrm{pH}$ 9,0), $0,25 \mathrm{mM}$ de cada dNTP, $1 \mathrm{mM}$ de cada primer, 5 unidades de Taq DNA polimerase (Pharmacia Biotech) e $2 \mathrm{ml}$ do DNA (aproximadamente $100 \mathrm{ng}$ ).

A amplificação foi realizada em um termociclador Perkin Elmer Cetus DNA e as condições de temperatura utilizadas foram 5 min a $94^{\circ} \mathrm{C}$, seguidos de 35 ciclos de 1 min a $94^{\circ} \mathrm{C}, 1 \min$ a $55^{\circ} \mathrm{C}$ e $1 \mathrm{~min}$ a $72^{\circ} \mathrm{C}, 5 \mathrm{~min}$ finais a $72^{\circ} \mathrm{C}$.

\section{Análise molecular por Southern blotting}

O DNA dos transformantes primários foi extraído pelo método descrito por Dellaporta et al. (1983) e, posteriormente, purificado por gradiente de cloreto de césio (Sambrook et al., 1989). Um total de $20 \mathrm{mg}$ de DNA de cada planta foi digerido com a enzima de restrição $\mathrm{XbaI}$ a $37^{\circ} \mathrm{C}$ por $16 \mathrm{~h}$, separado por eletroforese em gel de agarose $(0,8 \%)$ transferidos por capilaridade para membrana de náilon Hybond $\mathrm{N}$ (Amersham Life Science, 
Tabela 2. Efeito do período de co-cultivo na percentagem de explantes gus positivos (os números entre parênteses denotam o intervalo de confiança a 95\%). Brasília, Embrapa Hortaliças, 1999.

\begin{tabular}{cc}
\hline Período de co-cultivo (h) & $\begin{array}{c}\text { \% de explantes com porção } \\
\text { basilar GUS }+\end{array}$ \\
\hline 24 & $42(23-60)$ \\
48 & $66(47-83)$ \\
72 & $46(28-66)^{*}$ \\
96 & * \\
\hline
\end{tabular}

*Elevada contaminação

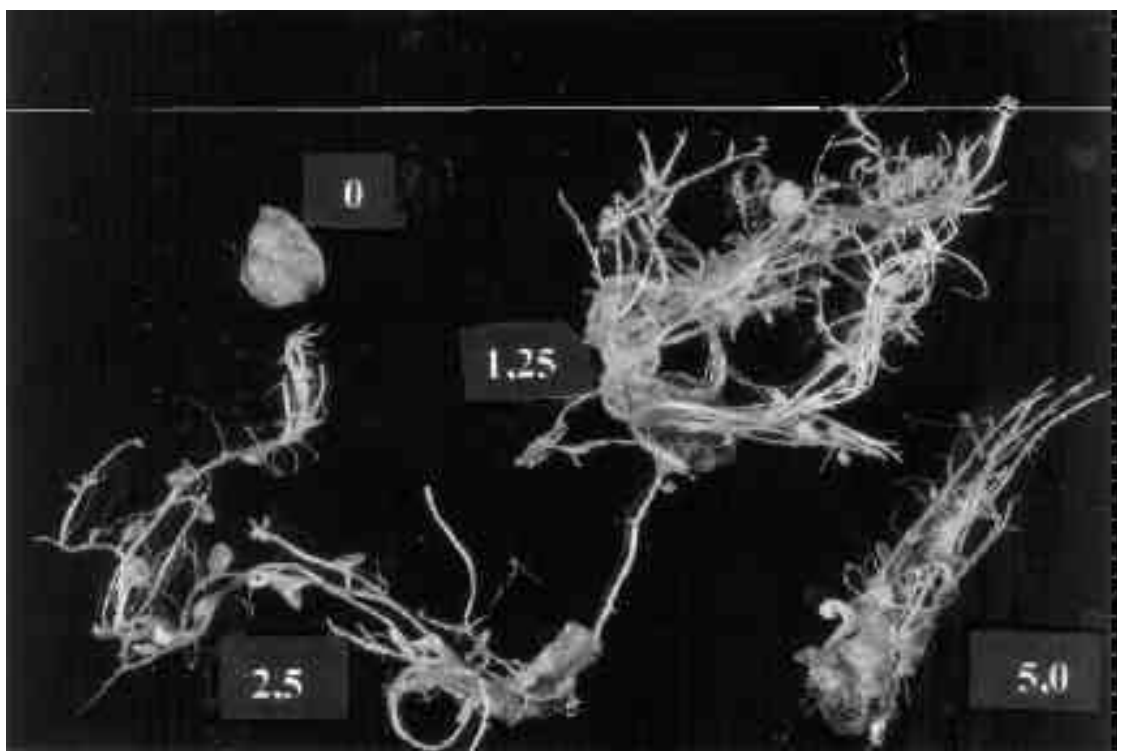

Figura 2. Regeneração de brotações em explantes de foliares em concentrações de zeatina em mg.L ${ }^{-1}$. Brasília, Embrapa Hortaliças, 1999.

Buckinghamshire, England) e hibridizados contra um fragmento interno do gene gus. A transferência e a hibridização foram realizadas essencialmente como descritas por Sambrook et al. (1989).

\section{RESULTADOS E DISCUSSÃO}

A adição de zea ao meio proporcionou a diferenciação de brotações nos explantes de segmentos nodais e foliares. Conforme observado na tabela 1 , os explantes de segmentos nodais foram mais eficazes para regeneração da cultivar Achat, nas condições estabelecidas. Maior número médio de brotações (3 por explante) foi verificado em segmentos nodais, em meio básico suplementado com 2,5 ou 5,0 mg.L${ }^{1}$ de zea (Tabela 1, Figura 1). Em explantes foliares, o máximo de brotações ocorreu na presença de 1,25 co-cultivo de 48 h também foi o mais adequado para a produção de plantas transgênicas.

Após o co-cultivo, os explantes foram imediatamente transferidos para meio de seleção contendo can, uma vez que as seleções tardias na presença desse antibiótico podem gerar quimeras que se perpetuam (Ferreira, 1998). Esse aspecto é importante uma vez que a batata se propaga vegetativamente.

A concentração de $50 \mathrm{mg} . \mathrm{L}^{-1}$ de can foi eficiente para selecionar propágulos potencialmente transformados. Observou-se que os segmentos nodais não transformados não mostraram processos morfogenéticos nessa concentração, morrendo após 20 a 30 dias. Porém, quando cultivados na ausência de can, esses explantes diferenciaram parte aérea (Figura 3). A utilização de can como agente seletivo também foi observada por Newell et al. (1991) que transformaram entrenós da cv. Russet Burbank com o gene da capa protéica do vírus $X$ e Y. Os explantes produziram brotações com uma freqüência de $60 \%$ na ausência de seleção e de $10 \%$ em meio com $100 \mathrm{mg} . \mathrm{L}^{-1}$ de can. Visser et al. (1989) analisaram brotações de batata regeneradas em meio com can, sendo que mais de $90 \%$ dessas eram transformadas. Trinca et al. (1990) também observaram que a presença de can no meio de regeneração foi eficiente na produção de até $100 \%$ de brotações de batata cv. Desirée resistentes a esse antibiótico e expressando o gene gus.

Nesse trabalho foi observado que, aproximadamente, $60 \%$ dos explantes, transformados com a construção gusintron, quando incubados na presença do substrato X-Glu, mostraram expressão constitutiva desse gene, confirmando o evento de transformação. Porém, a regeneração de brotações foi de $12 \%$. Esse resultado indica que somente células vegetais competentes para transformação e regeneração são capazes de diferenciar parte aérea em meio seletivo, sendo baixa a percentagem das células que possuíam esses dois atributos (Potrykus, 1990). Propágulos regenerados foram analisados e apresentaram, também, atividade constitutiva da enzima b-glucuronidase.

A adição de 100 mg. $\mathrm{L}^{-1}$ de cefotaxima e de $250 \mathrm{mg} \cdot \mathrm{L}^{-1}$ de 
carbenicilina ao meio foi adequada para controlar o crescimento da $A$. tumefaciens nos tecidos dos explantes após o co-cultivo, não apresentando efeito deletério na regeneração de brotações.

Os propágulos obtidos foram enraizados em meio com $0,05 \mathrm{mg} . \mathrm{L}^{-1} \mathrm{de}$ ANA. As plantas produzidas foram transferidas para casa de vegetação. Ensaios histoquímicos de gus, nessa nova condição ambiental, demonstraram que não houve modificação no padrão de expressão desse gene.

Em adição aos ensaios histoquímicos para confirmação da transgenicidade das plantas obtidas, foram realizados Polymerase Chain Reaction (PCR) e Southern blotting. Essa última técnica é considerada uma prova definitiva da integração do T-DNA no genoma vegetal (Potrykus, 1991). No ensaio de PCR, o DNA de 15 plantas potencialmente transformadas foi analisado utilizando-se oligonucleotídeos que amplificam um fragmento específico do gene npt II. A análise dos resultados indicou que todas as plantas tinham sido transformadas ( $\mathrm{Fi}^{-}$ gura 4). Um total de três plantas positivas nos ensaios histoquímicos para gus e PCR foi analisado por Southern blotting (Figura 5). O resultado evidenciou a integração do T-DNA no genoma vegetal.

Os resultados obtidos nesse trabalho são importantes devido à ineficácia dos protocolos prévios de transformação aplicados para a cultivar Achat. Foram otimizadas as condições de cultura que permitissem maior potencial de regeneração dos explantes e as condições que mediassem a transferência de genes nessa cultura. A cultivar Achat continua sendo uma das mais plantadas no Brasil devido a uma série de características quantitativas (poligênicas) incluindo tolerância a murcha bacteriana. A tecnologia descrita aqui poderá ser utilizada como procedimento padrão para introduzir outras características de interesse agronômico nesse genótipo, de maneira eficiente, em curto período de tempo.

\section{AGRADECIMENT OS}

Os autores agradecem ao Conselho Nacional de Desenvolvimento Científico e Tecnológico (CNPq) pelas bolsas concedidas e à FAP-DF pelo apoio financeiro.

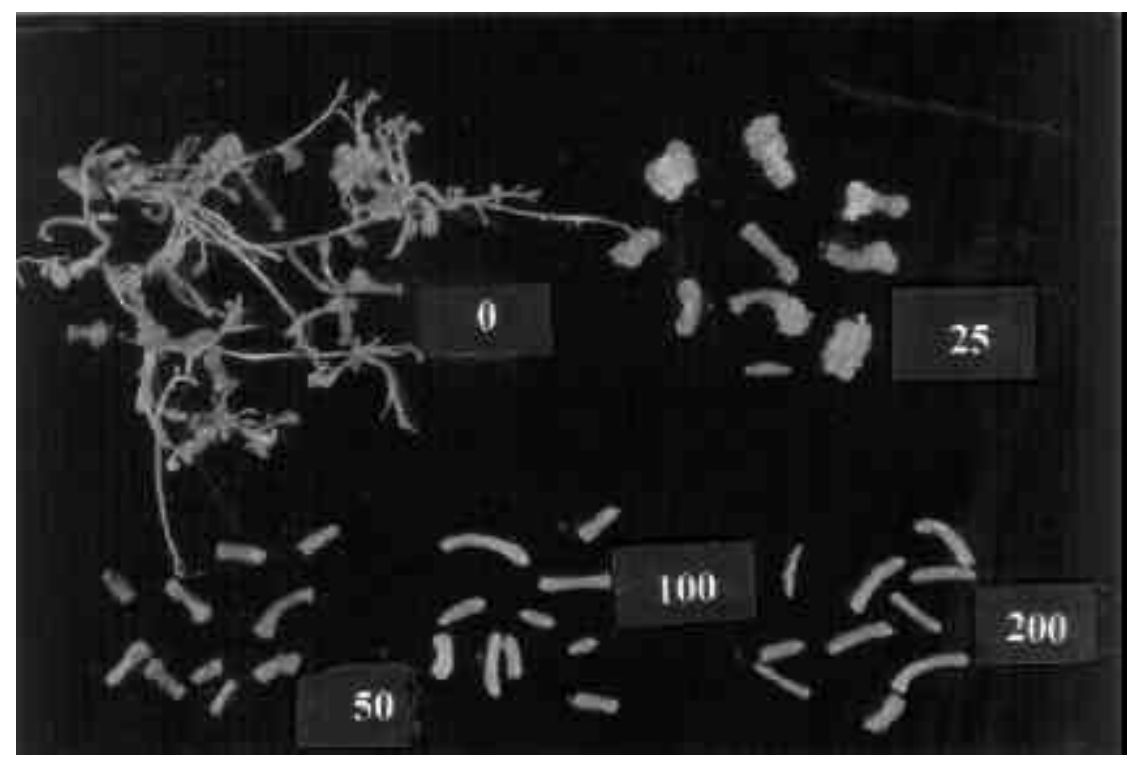

Figura 3. Sensibilidade de explantes de segmentos nodais de batata Achat às diferentes concentrações de canamicina, em mg.L $\mathrm{L}^{-1}$. Brasília, Embrapa Hortaliças, 1999.

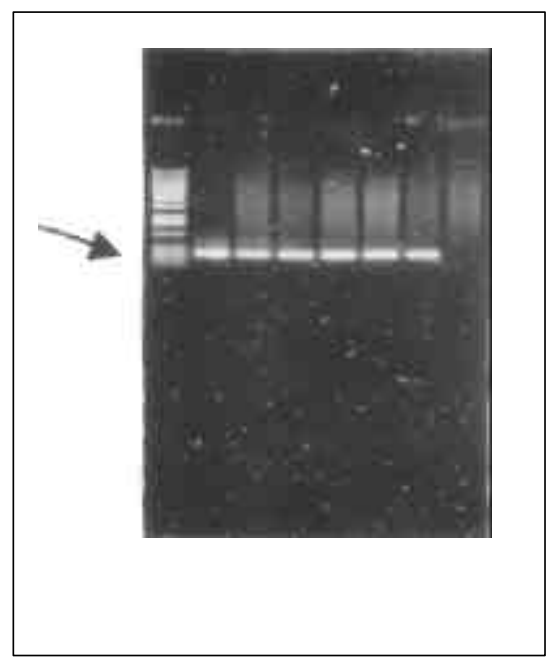

Figura 4. Análise eletroforética dos fragmentos amplificados via PCR usando primers específicos do gene NPT II, a partir de DNA extraído de plantas de batata cv Achat potencialmente transgênicas. Da esquerda para a direita: 1. Marcador de DNA, 1 KB DNA Ladder; 2. Controle positivo; 3, 4, 5, 6 e 7 amplificação a partir de plantas transgênicas; 8 . Controle negativo (planta não transgênica). A seta indica o fragmento de $460 \mathrm{pb}$ correspondente ao segmento do gene nptII. Brasília, Embrapa Recursos Genéticos e Biotecnologia, 1999.

\section{REFERÊNCIAS}

DELLAPORTA, S.L.; WOOD, J.; HICKS, J.B. A plant DNA minipreparation: version II. Plant Molecular Biology Report, v. 1, p. 1921, 1983.

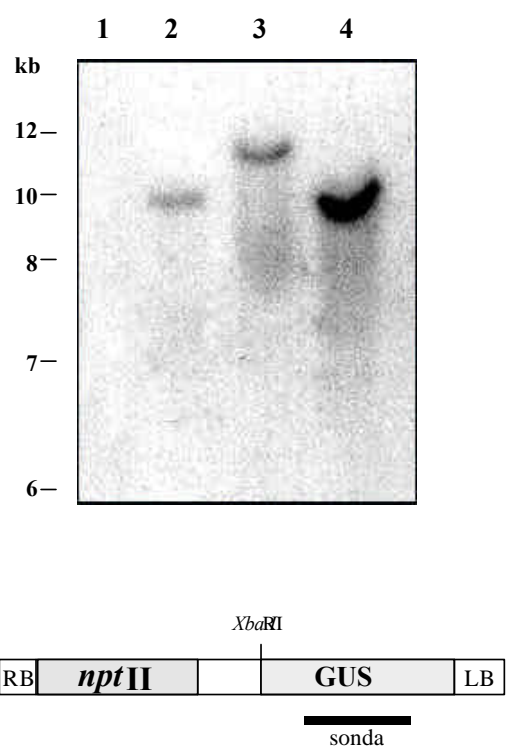

Figura 5. Análise por Southern blotting dos transformantes primários. DNAs foram digeridos com $X b a$ I, transferidos para membrana de náilon e hibridizados com fragmento interno do gene gus. Linha 1, planta não transgênica; linha 2-4, transformantes independentes. Os tamanhos dos fragmentos do marcador de peso molecular estão indicados à esquerda (RB: borda direita; LB: borda esquerda). Brasília, Embrapa Recursos Genéticos e Biotecnologia, 1999. 
FERREIRA, A.T. Transformação de batata (Solanum tuberosum L. cvs. Baronesa e Macaca) via Agrobacterium tumefaciens visando a obtenção de plantas resistentes ao vírus do enrolamento das folhas (PLRV). Pelotas, Universidade Federal de Pelotas, 1998, 112 p. (Dissertação mestrado).

FORREITER, C.; KIRSCHNER, M.; NOVER, L. Stable transformation of an Arabidopsis cell suspension culture with firefly luciferase providing a cellular system for analysis of chaperone activity in vivo. Plant Cell, v. 9, p. 2171-2181, 1997.

JEFFERSON, R.A. Assaying chimeric genes in plants: the GUS gene fusion system. Plant Molecular Biology Reporter, v. 5, p. 387-405, 1987.

MURASHIGE, T.; SKOOG, F. A revised medium for rapid growth and bioassays with tobacco tissue cultures. Physiologia Plantarum, v. 15, p. 473-497, 1962.

NEWELL, C.A.; ROZMAN, R.; HINCHEE, M.A.; LAWSON, E.C.; HALEY, L.; SANDERS, P; KANIEWSKI, W.; TUMER, N.E.; HORSCH, R.B.; FRALEY, R.T. Agrobacterium-mediated transformation of Solanum tuberosum L. cv. 'Russet Burbank'. Plant Cell Report, v. 10, n. 1, p. 30-34, 1991.

POTRYKUS, I. Gene transfer to cereals: an assessment. Biotechnology, v. 8, p. 535-541, 1990.
Gene transfer to plants: assessment of published approaches and results. Annual Review of Plant Physiology and Molecular Biology, v. 42, p. 205-225, 1991.

SAMBROOK, J.; FRITSCH, E.F.; MANIATIS, T. Molecular cloning: A laboratory manual. Second Edition. Cold Spring Harbor Laboratory Press, New York, 1989.

SCHOLTHOF, K.B.; SCHOLTHOF, H.B.; JACKSON, A.O. Control of plant virus diseases by pathogen-derived resistance in transgenic plants. Plant Physiology, v. 102, p. 7-12, 1993.

SHEERMAN, S.; BEVAN, M.W. A rapid transformation method for Solanum tuberosum using binary Agrobacterium tumefaciens vectors. Plant Cell Reports, v. 7, p. 13-16, 1988.

SOUZA, E.L.S; SOUZA, J.A. Produção de plantas de batata livre de vírus. In Anais do $1^{\circ}$ simpósio nacional de cultura de tecidos vegetais. Brasília, Embrapa/DDT, 1986. 109 p.

TORRES, A.C.; CANTLIFFE, D.J.; LAUGHNER, B.; BIENIEK, M. NAGATA, R.; FERL, R.J. Stable transformation of lettuce cultivar South Bay from cotyledon explants. Plant Cell, Tissue and Organ Culture, v. 34, p. 279-285, 1993.
TORRES, A.C.; NAGATA, R.; FERL, R.J. BEWICK, T.A.; CANTLIFFE, D.J. In vitro assay selection of glyphosate resistance in lettuce. Journal of American Society for Horticultural Science, v. 124, n. 1, p. 86-89, 1999.

TRINCA, S.; DE PACE, C.; CACCIA, R.; MUGNOZZA, G.S.; DODDS, J.H.; JAYNES, J. Transformation of potato (Solanum tuberosum L.) leaf disc using A. tumefaciensmediated transfer of DNA sequences coding for lytic peptides. In: Molecular methods for potato improvement. Report of the planning conference on "Application of molecular techniques to potato germplasm enhancement". Lima, Peru, 5-9 March, 1990. Lima, CIP. 188 p.

VAYDA, M.E.; BELKNAP, W.R. The emergence of transgenic potatoes as commercial products and tools for basic science. Transgenic Research, v. 1, p. 149-163, 1992.

VISSER, R.G.F.; JACOBSEN, E.; HESSELINGMEINDERS, A.; SCHANS, M.J.; WITHOLT, B.; FEENSTRA, W.J. Transformation of homozygous diploid potato with an Agrobacterium tumefaciens binary vector system by adventitious shoot regeneration on leaf and stem segments. Plant Molecular Biology, v. 12, p. 329-337, 1989. 